\title{
Ultrasound-Assisted Extraction of Phenolic Compounds from Moroccan Lavandula stoechas L.: Optimization Using Response Surface Methodology
}

\author{
Yassine Ez zoubi $\mathbb{D}^{1,2}$ Mouhcine Fadil, ${ }^{3}$ Dalila Bousta, ${ }^{4}$ Abdelhakim El Ouali Lalami, ${ }^{5}$ \\ Mohammed Lachkar $\left(\mathbb{D},{ }^{6}\right.$ and Abdellah Farah ${ }^{2}$ \\ ${ }^{1}$ Biotechnology, Environmental Technology and Valorization of Bio-Resources Team, Department of Biology, \\ Faculty of Science and Technology Al-Hoceima, Abdelmalek Essaadi University, Tetouan, Morocco \\ ${ }^{2}$ Laboratory of Applied Organic Chemistry, Faculty of Sciences and Technology, Sidi Mohamed Ben Abdellah University, \\ B.P. 2202-Route d'Imouzzer, Fez, Morocco \\ ${ }^{3}$ Physico-Chemical Laboratory of Inorganic and Organic Materials, Materials Science Center (MSC), Ecole Normale Supérieure, \\ Mohammed V University in Rabat, Rabat, Morocco \\ ${ }^{4}$ Laboratory of Biotechnology Environment Agri-Food and Health, Faculty of Sciences, Sidi Mohamed Ben Abdellah University, \\ P.O. Box 1796 (Atlas), Fez, Morocco \\ ${ }^{5}$ Higher Institute of Nursing Professions and Health Techniques of Fez, Regional Health Directorate Fez-Meknes, \\ El Ghassani Hospital, Fez, Morocco \\ ${ }^{6}$ Engineering Laboratory of Organometallic, Molecular Materials and Environment (LIMOME), Faculty of Sciences, \\ Sidi Mohamed Ben Abdellah University, P.O. Box 1796 (Atlas), Fez, Morocco \\ Correspondence should be addressed to Yassine Ez zoubi; ezzoubiyassine@yahoo.fr
}

Received 29 September 2020; Revised 17 December 2020; Accepted 20 December 2020; Published 13 January 2021

Academic Editor: Claudio Cameselle

Copyright (c) 2021 Yassine Ez Zoubi et al. This is an open access article distributed under the Creative Commons Attribution License, which permits unrestricted use, distribution, and reproduction in any medium, provided the original work is properly cited.

\begin{abstract}
Secondary plant metabolites, in particular phenolic compounds, are characterized by great diversity in the plant kingdom and are widely used in the medical and industrial fields. The extraction of these compounds represents a critical step, and the differences in extraction conditions strongly affect the yields and the total concentrations of polyphenols in the extracts. In this way, the objective of the present study was to optimize the extraction parameters of the polyphenols from Lavandula stoechas using the extraction technique assisted by ultrasound. Yield and the total concentration of polyphenols have been optimized, taking into account three variables, the extraction time ( $\mathrm{min})$, the ethanol concentration (\%), and the solvent/extract ratio ( $\mathrm{ml} / \mathrm{g})$. The optimum extraction yield (31.88\%) was obtained by ensuring the following parameters: an ethanol concentration of $40 \%$, a liquid/solid ratio of $30 \mathrm{ml} / \mathrm{g}$, and a time processing of $32.62 \mathrm{~min}$. The maximum concentration of total polyphenols (190.14 $\mathrm{mg}$ gallic acid equivalents (GAE)/g) was obtained after $21.5 \mathrm{~min}$ of extraction, with a liquid/solid ratio of $30 \mathrm{ml} / \mathrm{g}$ and a concentration of ethanol at $40 \%$. In order to obtain the maximum yield (24.9\%) and the total concentration of polyphenols (190.14 mg GAE/g) simultaneously, the following parameters must be adjusted: an extraction time of $21.5 \mathrm{~min}$, a liquid/solid ratio of $30 \mathrm{ml} / \mathrm{g}$, and a concentration of ethanol at $40 \%$. The experimental values of the yield and the total concentration of the polyphenols were in good agreement with the predicted values, which suggests that the ultrasonic extraction model adopted in this study is validated.
\end{abstract}

\section{Introduction}

Therapeutic activities of plants have long been associated with the production of secondary metabolites, including alkaloids, flavonoids, tannins, terpenoids, coumarins, and mucilages. Polyphenols are abundant phytochemicals and constitute a large class of compounds which have attracted research attention due to their potential human health benefits [1]. They have attracted the attention of scientists for a long time, and several recent studies have proven the 
antioxidant activity [2], anti-inflammatory activity [3], prevention against cardiovascular disease [4], antibacterial [5], antifungal [6], hypoglycemic [7], antiviral [8], anticancer [9] activities, and many other diseases [4].

Lavandula stoechas is one of most plants used traditionally in the Mediterranean countries, including Morocco, for the treatment of painful illnesses such as inflammatory diseases, cystitis, nephritis, and rheumatic arthritis $[10,11]$. Several studies have reported that the aqueous and alcoholic extracts of $L$. stoechas are characterized by various biological effects. Indeed, [12, 13], antifungal [14], antioxidant [14, 15], antihyperglycemic activities [16], anticonvulsant, antispasmodic, and sedative effects [17], and anti-inflammatory activity [17-19] have been reported. These activities are related to the phenolic compounds identified in the extracts of $L$. stoechas. Phenolic acids and flavone glycosides are the most reported phenolic compounds in L. stoechas extracts $[14,20,21]$.

Ultrasound-assisted extraction (UAE) is an innovative and promising technique used in several fields such as cosmetics, pharmaceutical, chemical, and food industries since the second half of the $20^{\text {th }}$ century [22]. Recently, several studies indicate that ultrasound produces more abundant extracts in biomolecules and in a shorter extraction time compared to conventional extraction techniques [22, 23]. A study realized by Chemat et al. [24] showed that the yield of carvone extracted from caraway seeds (Carum carvi L.) is best in ultrasound-assisted extraction as those given by the Soxhlet extract. A comparative study on the extraction of phenolic compounds from the flowers and buds of Acacia confusa was carried out by ultrasound, maceration, and extraction assisted by heat. This study confirmed that ultrasonic extraction is the most rapid and efficient technique, which allows to significantly increase the rate of phenolic content compared to other methods studied [25]. According to several studies, the quality of the phenolic compounds and the total concentration of polyphenols in several matrices extracted by ultrasound depends on the quantity and the polarity of the solvent used, the ultrasonic intensity [26], the extraction temperature [27], and the extraction time [28].

The aim of this work was to maximize the obtained yield and total phenolic contents from L. stoechas extracted by ultrasound method. In order to achieve this objective, we used the Box-Behnken design in conjunction with a response surface methodology (RSM) to optimizing three parameters: the extraction time (min), liquid/solid ratio (ml/ g), and ethanol concentration (\%).

\section{Material and Methods}

2.1. Plant Material. The aerial parts (leaves, stems, and flowers) of $L$. stoechas were harvested during the period of April to May 2016 in the commune of Timezgana ( $34^{\circ} 33^{\prime} 02.7^{\prime \prime}$ $\mathrm{N} 4{ }^{\circ} 40^{\prime} 49.3^{\prime \prime} \mathrm{W}$ ) in Taounate Province (north central region of Morocco), at an altitude of approximately $800 \mathrm{~m}$. The botanical identification was realized by Professor Abdeslam Ennabili, botanist and Head of the Phytology Department in the National Institute of Medicinal and Aromatic Plants, Taounate, Morocco. Authenticated voucher specimens have been deposited in the Herbarium of the National Institute of Medicinal and Aromatic Plants, Morocco.

2.2. The Ultrasound-Assisted Extraction. The extraction method was performed with ultrasound cleaning bath Elma Transsonic TI-H-15 (a frequency of $35 \mathrm{kHz}$ and a nominal power of $100 \mathrm{~W})$. The powder of the dried plants $(20 \mathrm{~g})$ was placed in a capped tube $(100 \mathrm{ml})$ and mixed with an appropriate amount of the extraction solution (according to experimental design). The tube with the suspension was immersed in water in the ultrasonic device and irradiated for the preset extraction time. After ultrasonic extraction, the sample was filtered by Whatman paper and evaporated under vacuum at $40^{\circ} \mathrm{C}$ on a rotary evaporator.

2.3. Experiment Design. Response surface methodology (RSM) was used for investigating the influence of three independent variables on yield and total phenols of $L$. stoechas extracts. The extraction time (min, X1), liquid/solid ratio (ml/ $\mathrm{g}, \mathrm{X} 2)$, and ethanol concentration (\%, X3) were selected as independent variables that should be optimized for the extraction. The samples were kept at room temperature to avoid the degradation of temperature-sensitive compounds. In the study, the experiments were performed on the Box-Behnken design (BBD). The level values of the experimental factors are shown in Table 1.

2.4. Determination of Total Phenolic Content. The Folin-Ciocalteu method was used to determine the total phenolic content (TPC) of the extract with slight modifications [29]. TPC was estimated in milligrams of gallic acid equivalents per gram of dry plant material (mg of GAE/g). $100 \mu \mathrm{l}$ of the sample $(1 \mathrm{mg} / \mathrm{ml})$ was transferred to a $10 \mathrm{ml}$ volumetric flask, to which $500 \mu \mathrm{l}$ undiluted Folin-Ciocalteu reagent was added subsequently. After $1 \mathrm{~min}, 1.5 \mathrm{ml}$ of $20 \%$ (w/v) $\mathrm{Na}_{2} \mathrm{CO}_{3}$ was added and the volume was made up to $10 \mathrm{ml}$ with $\mathrm{H}_{2} \mathrm{O}$. After 2 hours of incubation at $25^{\circ} \mathrm{C}$, the absorbance was measured at $765 \mathrm{~nm}$ and compared to the gallic acid calibration curve.

2.5. Statistical Analysis. The experimental results of the response surface design were analyzed using JMP software (version 10) [30]. The main effect of regression was considered to be statistically significant for $p$ values less than 0.05. All experiments were conducted in triplicate unless otherwise noted in the text.

The complete design was carried out in random order and consisted of 15 combinations, including three replicates in the central point. The data from the Box-Behnken design (BBD) were analyzed by multiple regressions to fit the following quadratic polynomial model: 
TABLE 1: The selected factors and their levels in the Box-Behnken design.

\begin{tabular}{lccccc}
\hline \multirow{2}{*}{ Factors } & \multirow{2}{*}{ Unity } & \multirow{2}{*}{ Symbol } & \multicolumn{3}{c}{ Factor level } \\
& & & -1 & 0 & 1 \\
\hline Extraction time & $\mathrm{Min}$ & $\mathrm{X} 1$ & 20 & 30 & 40 \\
Solvent-to-material ratio & $\mathrm{m} / \mathrm{g}$ & $\mathrm{X} 2$ & 20 & 25 & 30 \\
Ethanol & $\%$ & $\mathrm{X} 3$ & 40 & 60 & 80 \\
\hline
\end{tabular}

$$
\begin{aligned}
Y= & b_{0}+b_{1} X_{1}+b_{2} X_{2}+b_{3} X_{3}+b_{11} X_{1}^{2}+b_{22} X_{2}^{2}+b_{33} X_{3}^{2} \\
& +b_{12} X_{1} X_{2}+b_{13} X_{1} X_{3}+b_{23} X_{2} X_{3}+\varepsilon,
\end{aligned}
$$

where $Y$ is the studied response; $b_{0}$ represents the average value of responses; $b_{1}, b_{2}$, and $b_{3}$ are coefficients of the main terms; $b_{11}, b_{22}$, and $b_{33}$ are the coefficients of quadratic terms; $b_{12}, b_{13}$, and $b_{23}$ are the coefficients of the interaction terms; and $\varepsilon$ is an error term.

An analysis of variance with $F$ test at a $95 \%$ significance level was conducted. The mean squares (MS) were obtained as follows: MS $=(\mathrm{SS} / \mathrm{DF})$, where SS is the sum of squares of each variation source and DF is the respective degree of freedom.

The ratio between the mean square regression $\left(\mathrm{MS}_{R}\right)$ and the mean square residual $\left(\mathrm{MS}_{r}\right), F_{\text {ratio(R/r) }}$, was used in order to establish whether the model was statistically significant [31]. The greater $F$-value from unity adequately explains the variation of the data around its mean. Besides, the estimated factor effects are real [32].

The quality of fitting the first-order polynomial was also expressed with the coefficient of determination $R^{2}$. This coefficient measures the proportion of total variation in the mean response explained by the regression. In fact, it represents the correlation between the observed and predicted responses, and it is often expressed as a percentage [33].

The model coefficients were considered significant for $p$ values $<0.05$. The statistical significance of the model coefficients was determined by using the $t$-test (only significant coefficients with $p$ value $<0.05$ are included).

2.6. Optimization of Operating Conditions. The isoresponse curves were used to find the optimal agreement between operating conditions. These are surface curves that reflect the changes in the response. Moreover, the "desirability" function was used to find the exact optimal combination with a percentage of compromise.

\section{Results}

3.1. Experimental Design. Table 2 shows the yield and TPC of L. stoechas extracts obtained from all experiments.

3.2. Statistical Validation of the Postulated Model. According to the analysis of variance table (Table 3), we can conclude that the main effect of regression is significant for both the studied responses since the significance of the risk ( $p$ value) is lower than 0.05 . Obviously, for the two studied responses, the calculation of $F_{\text {Ratio }(R / r)}(13.93$ for the response yield and 6.59 for the response TPC) has shown that it is higher than the theoretical value of $F_{(0.05 ; 9,5)}$ at $95 \%$ confidence level which is equal to 4.77 .

The linear regression of the model permitted us to evaluate the quality of the established model graphically. It is represented by the linearity of the points measured by the real model according to the points considered by the quadratic model. The goodness of the model is judged if the coefficient of determination is equal to or higher than $80 \%$. The coefficients of determination $R^{2}$ are equal to $96 \%$ and $92 \%$ for the response yield and TPC, respectively. These values give a good agreement between the experimental and predicted values of the adapted model. These results are confirmed by those obtained in the graph (Figure 1), showing a linear curve for the observed values in terms of the predicted ones.

3.3. Study of the Factor's Effects and the Fitted Model for the Response Yield. The effects of all factors studied and the statistical values of Student's $t$-test and the observed probability ( $p$ value) are summarized in Table 4 . Student's $t$ test values are used to determine the significance of the coefficients of each parameter, while $p$ values are defined as the smallest level of importance, leading to rejection of $\mathrm{HO}$ $\left(b_{i}=0 ; \alpha=0.05\right)$. Thus, Table 4 shows that all factors can be considered as significant since their $p$ values are lower than 0.05 except factor $b_{1}$ and factor $b_{13}$, which can be considered as negligible ( $p$ value $>0.05$ ).

The equation of the quadratic model used for the modeling extraction conditions of yield, determined according to the results of the JMP 10 software, was represented as follows:

$$
\begin{aligned}
Y 1= & 21.62+4.42 X_{2}-2.13 X_{3}-3.7 X_{1}^{2}-3.98 X_{2}^{2}+3.44 X_{3}^{2} \\
& +2.75 X_{1} X_{2}-3.28 X_{2} X_{3}+\varepsilon .
\end{aligned}
$$

3.4. Study of the Factor's Effects and Fitted Model for the Response TPC. The effects of all factors studied and the statistical values of Student's $t$-test and the observed probability ( $p$ value) are summarized in Table 5 . These results show that the factors $b_{0}^{\prime}, b_{1}^{\prime}, b_{3}^{\prime}, b_{11}^{\prime}, b_{22}^{\prime}$ can be considered as statistically significant since their $p$ values are lower than 0.05 .

The equation of the quadratic model used for the total polyphenols, determined according to the results of the JMP 10 software, was represented as follows:

$$
Y 2=91.86-15.45 X_{1}-16.22 X_{3}+36.63 X_{1}^{1}+27.47 X_{2}^{2}+\varepsilon .
$$

3.5. Response Surface Optimization. Using the isoresponse curves, we can consider options regarding operating conditions. With manual adjustment of target values of the two 
TABLE 2: Different combinations generated by the Box-Behnken design and the recorded responses for each experiment of L. stoechas extracts.

\begin{tabular}{|c|c|c|c|c|c|}
\hline Experiment number & Extraction time (min) & Liquid/solid ratio $(\mathrm{ml} / \mathrm{g})$ & Ethanol concentration (\%) & Yield (\%) & TPC (mg GAE/g) \\
\hline 1 & 20 & 20 & 60 & 12.33 & 180.82 \\
\hline 2 & 40 & 20 & 60 & 7.00 & 144.13 \\
\hline 3 & 20 & 30 & 60 & 15.33 & 184.36 \\
\hline 4 & 40 & 30 & 60 & 21.03 & 115.63 \\
\hline 5 & 20 & 25 & 40 & 22.71 & 149.53 \\
\hline 6 & 40 & 25 & 40 & 26.60 & 147.48 \\
\hline 7 & 20 & 25 & 80 & 16.60 & 124.57 \\
\hline 8 & 40 & 25 & 80 & 19.53 & 108.37 \\
\hline 9 & 30 & 20 & 40 & 14.19 & 130.53 \\
\hline 10 & 30 & 30 & 40 & 29.93 & 149.53 \\
\hline 11 & 30 & 20 & 80 & 18.80 & 118.80 \\
\hline 12 & 30 & 30 & 80 & 21.40 & 95.52 \\
\hline 13 & 30 & 25 & 60 & 22.33 & 89.38 \\
\hline 14 & 30 & 25 & 60 & 20.80 & 95.33 \\
\hline 15 & 30 & 25 & 60 & 21.73 & 90.87 \\
\hline
\end{tabular}

TABle 3: Analysis of variance for the fitted models.

\begin{tabular}{lccccccccc}
\hline \multicolumn{9}{c}{ Yield (\%) } & \multicolumn{3}{c}{ TPC } \\
\hline Model & DF & SS & MS & $F$ & $p$-value & DF & SS & MS & $F$ \\
\hline$R$ & 9 & 434.62 & 48.29 & 13.94 & 0.005 & 9 & 12142.34 & 1349.15 & 6.60 \\
$R$ & 5 & 17.32 & 3.46 & & & 5 & 1022.80 & 204.56 & 0.03 \\
Total & 14 & 451.95 & & & & 14 & 13165.14 & & \\
\hline
\end{tabular}

DF: degrees of freedom; SS: sum of squares; MS: mean square; $R$ : regression; $r$ : residual.

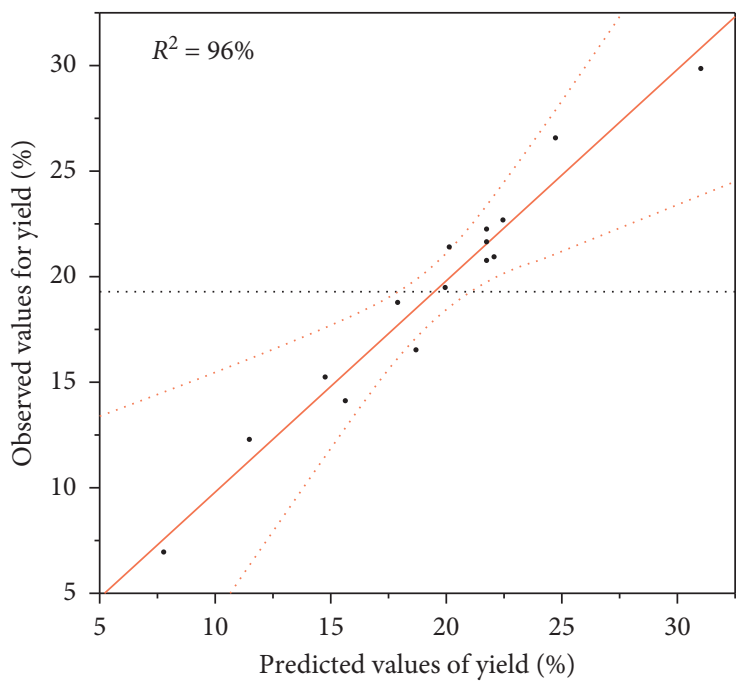

(a)

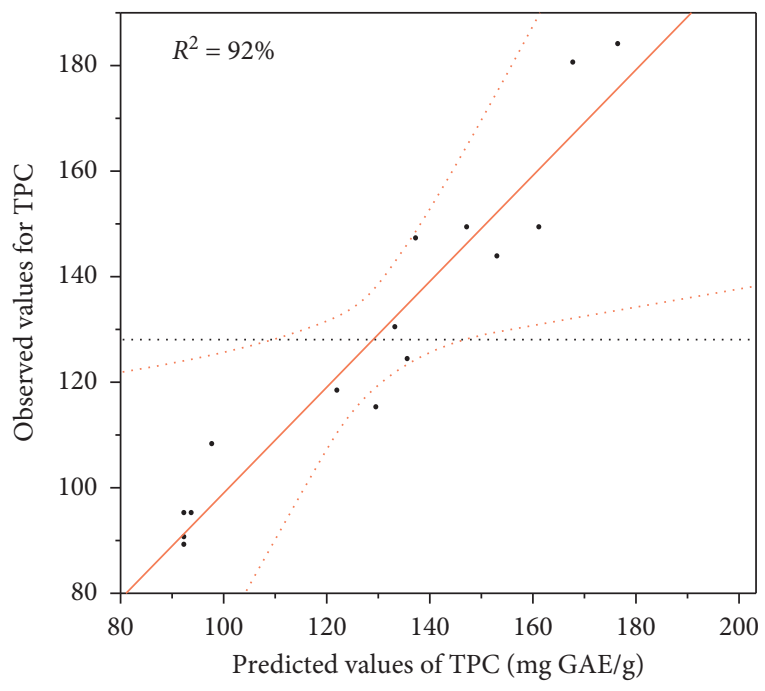

(b)

Figure 1: Curves of the observed values in terms of the predicted values for the two studied responses (a) yield and (b) TPC.

studied answers, one is interested in the most advantageous economical experimental conditions. Then, it is advantageous to use the least amount of ethanol in a time interval somewhat weak.

3.5.1. Optimization of the Yield Response. The desirability plot (Figure 2) shows that the maximum yield that we can have is around $31.88 \%$. We can also see that obtaining this value is possible with a desirability of $98.7 \%$. This same plot also shows that the maximal value of yield requires a minimal concentration of ethanol (40\%), a maximum solvent-to-material ratio $(30 \mathrm{ml} / \mathrm{g})$, and a time processing higher than $30 \mathrm{~min}$. By fixing the concentration of ethanol at $40 \%$ in the isoresponse plot, we can see that the required time for obtaining this yield is between 30 and $40 \mathrm{~min}$ when the liquid/solid ratio must be between 28 and $30 \mathrm{ml} /$ g (Figure 3(a)). The 3D plot (Figure 3(b)) shows the 
TABLE 4: Estimated regression coefficients for the yield response and their level of significance $p$ value.

\begin{tabular}{|c|c|c|c|c|}
\hline Term & Coefficient & Estimation & Standard deviation & $p$-value \\
\hline Constant & $b_{0}$ & 21.62 & 1.075 & $<0.0001^{* * *}$ \\
\hline Extraction time & $b_{1}$ & 0.899 & 0.658 & 0.23 \\
\hline Solvent-to-material ratio & $b_{2}$ & 4.421 & 0.658 & $0.001^{* *}$ \\
\hline Ethanol (\%) & $b_{3}$ & -2.138 & 0.658 & $0.023^{*}$ \\
\hline Extraction time $*$ solvent-to-material ratio & $b_{12}$ & 2.758 & 0.931 & $0.031^{*}$ \\
\hline Extraction time $*$ ethanol $(\%)$ & $b_{13}$ & -0.24 & 0.931 & 0.806 \\
\hline Solvent-to-material ratio $*$ ethanol $(\%)$ & $b_{23}$ & -3.285 & 0.931 & $0.017^{*}$ \\
\hline Extraction time $*$ extraction time & $b_{11}$ & -3.709 & 0.969 & $0.012^{*}$ \\
\hline Solvent-to-material ratio $*$ solvent-to-material ratio & $b_{22}$ & -3.989 & 0.969 & $0.009^{*}$ \\
\hline Ethanol $(\%) *$ ethanol (\%) & $b_{33}$ & 3.449 & 0.969 & $0.016^{*}$ \\
\hline
\end{tabular}

${ }^{* * *} p<0.05,{ }^{* *} p<0.01$, and ${ }^{*} p<0.001$.

TABLE 5: Estimated regression coefficients for the response total polyphenol concentration and their level of significance $p$ value.

\begin{tabular}{|c|c|c|c|c|}
\hline Term & Coefficient & Estimation & Standard deviation & $p$-value \\
\hline Constant & $b_{0}^{\prime}$ & 91.86 & 8.258 & $0.0001^{* * *}$ \\
\hline Extraction time & $b_{1}^{\prime}$ & -15.459 & 5.057 & $0.028^{*}$ \\
\hline Solvent-to-material ratio & $b_{2}^{\prime}$ & -3.655 & 5.057 & 0.502 \\
\hline Ethanol (\%) & $b_{3}^{\prime}$ & -16.226 & 5.057 & $0.024^{*}$ \\
\hline Extraction time $*$ solvent-to-material ratio & $b_{12}^{\prime}$ & -8.01 & 7.151 & 0.314 \\
\hline Extraction time $*$ ethanol $(\%)$ & $b_{13}^{\prime \prime}$ & -3.538 & 7.151 & 0.642 \\
\hline Solvent-to-material ratio $*$ ethanol $(\%)$ & $b_{23}^{\prime}$ & -10.57 & 7.151 & 0.199 \\
\hline Extraction time $*$ extraction time & $b_{11}^{\prime}$ & 36.634 & 7.443 & $0.004^{* *}$ \\
\hline Solvent-to-material ratio $*$ solvent-to-material ratio & $b_{22}^{\prime}$ & 27.741 & 7.443 & $0.014^{*}$ \\
\hline Ethanol $(\%) *$ ethanol $(\%)$ & $b_{33}^{\prime}$ & 3.994 & 7.443 & 0.615 \\
\hline
\end{tabular}

${ }^{* * *} p<0.05,{ }^{* *} p<0.01$, and ${ }^{*} p<0.001$.
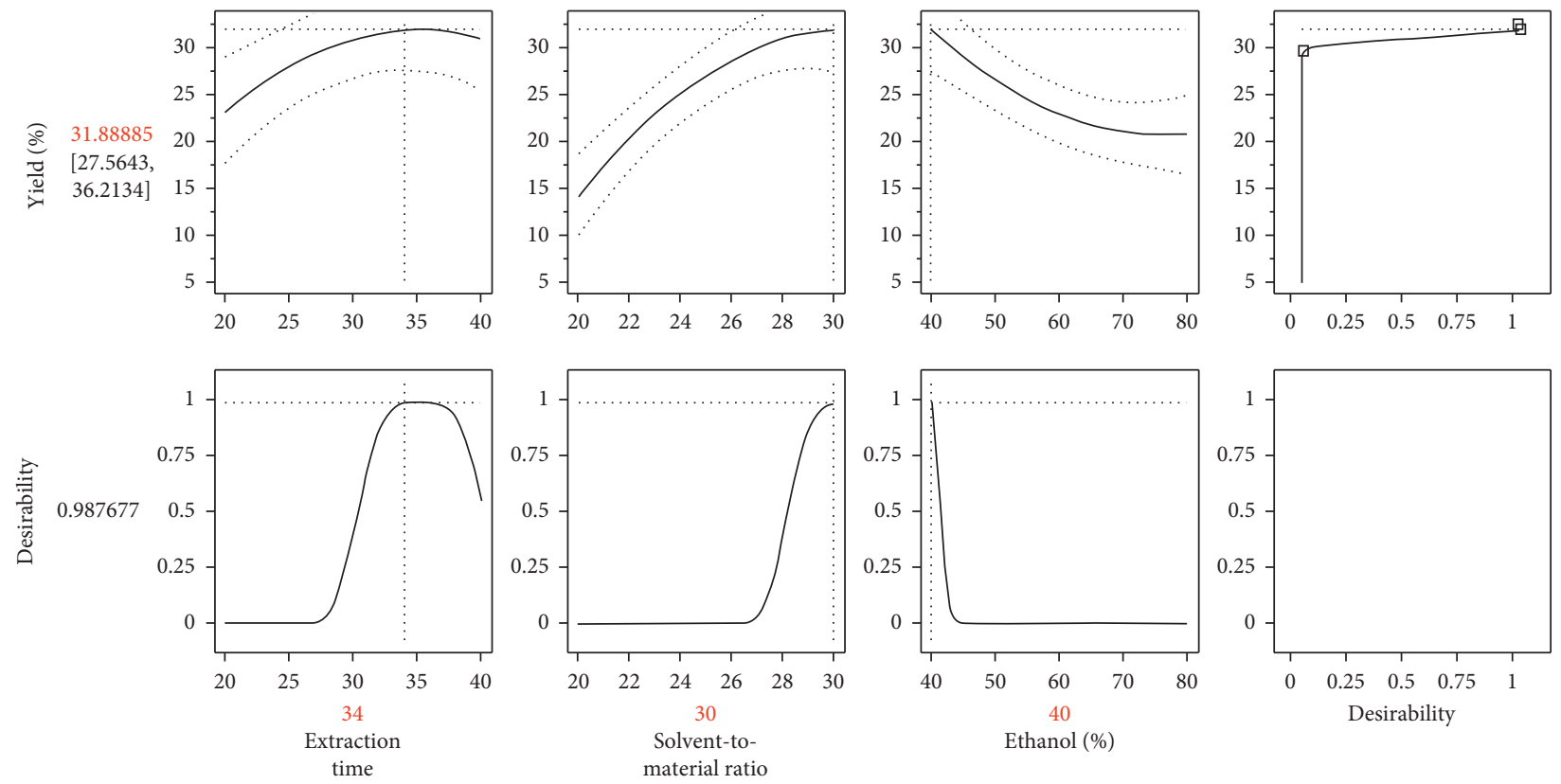

FIGURE 2: Desirability plot showing the precise operating conditions leading to the optimal yield.

graphical representation of the response yield in terms of extraction time and liquid/solid ratio and by fixing the parameter ethanol concentration (\%) on its low level (40\%).
3.5.2. Optimization of the Total Phenolic Content (TPC) Response. The desirability plot of this second response (TPC) (Figure 4) shows that the maximum value that we can obtain is around $190.14 \mathrm{mg} \mathrm{GAE} / \mathrm{g}$. Obtaining this response 




(a)

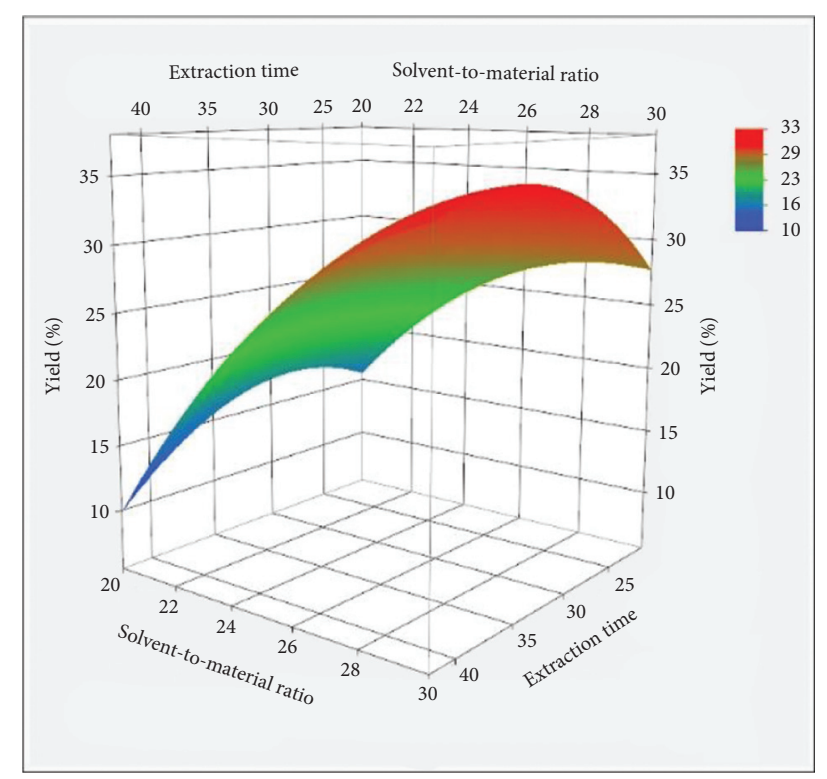

(b)

Figure 3: (a) Isoresponse plot showing the optimal compromise zone leading to the desired yield (31\%) obtained by fixing the third parameter (ethanol (\%)) in its low level (40\%) and varying the other two parameters. (b) 3D plot of the response yield (\%) in terms of extraction time and liquid/solid ratio effects and by fixing the concentration of ethanol at $40 \%$.

is possible with $98 \%$ desirability. As in the case of the extraction yield, the maximal TPC value that we can get requires a minimal concentration of ethanol (40\%), a minimal time processing, and a maximum liquid/solid ratio.

The isoresponse plot (Figure 5(a)) confirms the results of the desirability plot. Thus, this plot shows that the compromised area (white area) is accessible by ensuring a time between 20 and $21.5 \mathrm{~min}$ and a liquid/solid ratio between 28 and $30 \mathrm{ml} / \mathrm{g}$ and by fixing the concentration of ethanol at $40 \%$. The 3D plot (Figure 5(b)) shows the graphical representation of the response TPC in terms of extraction time and liquid/solid ratio and by fixing the parameter ethanol concentration (\%) on its low level (40\%).

\subsubsection{Optimization of Two Responses Simultaneously.} The obtained results for the two responses separately indicate that the maximization of two responses requires a reduction in the ethanol concentration to $40 \%$ and an increase in the liquid/solid ratio $(30 \mathrm{ml} / \mathrm{g})$. However, this shows disagreement as regards the time factor. When we have a maximum yield (31\%) performance requires a time longer than 30 minutes, the TPC response requires a minimal time (just 20 minutes) to reach its maximum. Since the interest of extraction is on TPC, we will adopt the setting that guarantees the maximization of TPC, as shown in the desirability plot (Figure 6). By adopting the optimum setting of maximizing TPC (time: $21.5 \mathrm{~min}$, liquid/solid ratio: $30 \mathrm{ml} /$ g, and ethanol concentration: $40 \%$ ), we will have a TPC equal to $190 \mathrm{mg} \mathrm{GEA} / \mathrm{g}$ with a yield of $24 \%$ (loss of $7 \%$ compared to the maximum possible yield $31 \%$ ). These results are obtained with a desirability of $99 \%$. The isoresponse plot for both answers shows a very small area (white area) of compromise between the two studied responses (Figure 7).

3.6. Verification of Predictive Model. To compare the predicted result with the experimental result, a control experiment randomly chosen from the experimental domain was performed. Experimental values of yield $(14.85 \pm 1.02 \%)$ and TPC $(130.15 \pm 2.35 \mathrm{mg} \mathrm{GAE} / \mathrm{g})$ were slightly higher than the predicted ones which were equal to $14.29 \%$ and TPC at $129.75 \mathrm{mg} \mathrm{GAE} / \mathrm{g}$ (Table 6). This result suggests that the optimized model explains appropriately the extraction process of yield and phenolic compounds. Moreover, the experimental validation provides preliminary information that the developed model can be successfully applied for predicting the optimal extraction time, the liquid/solid ratio, and the ethanol concentration.

\section{Discussion}

The objective of this study was to determine the levels of experimental factors that would allow to obtain maximum yield and a high concentration of polyphenols. In fact, to get the maximum yield and TPC, a compromise was found in choosing the optimal adjustment for the concentration of ethanol (40\%) and liquid/solid ratio $(30 \mathrm{ml} / \mathrm{g})$. However, a disagreement in extraction time was observed for the two responses. Response surface analysis demonstrates that the relationship between the total phenolic content and extraction parameters is quadratic with a good regression 

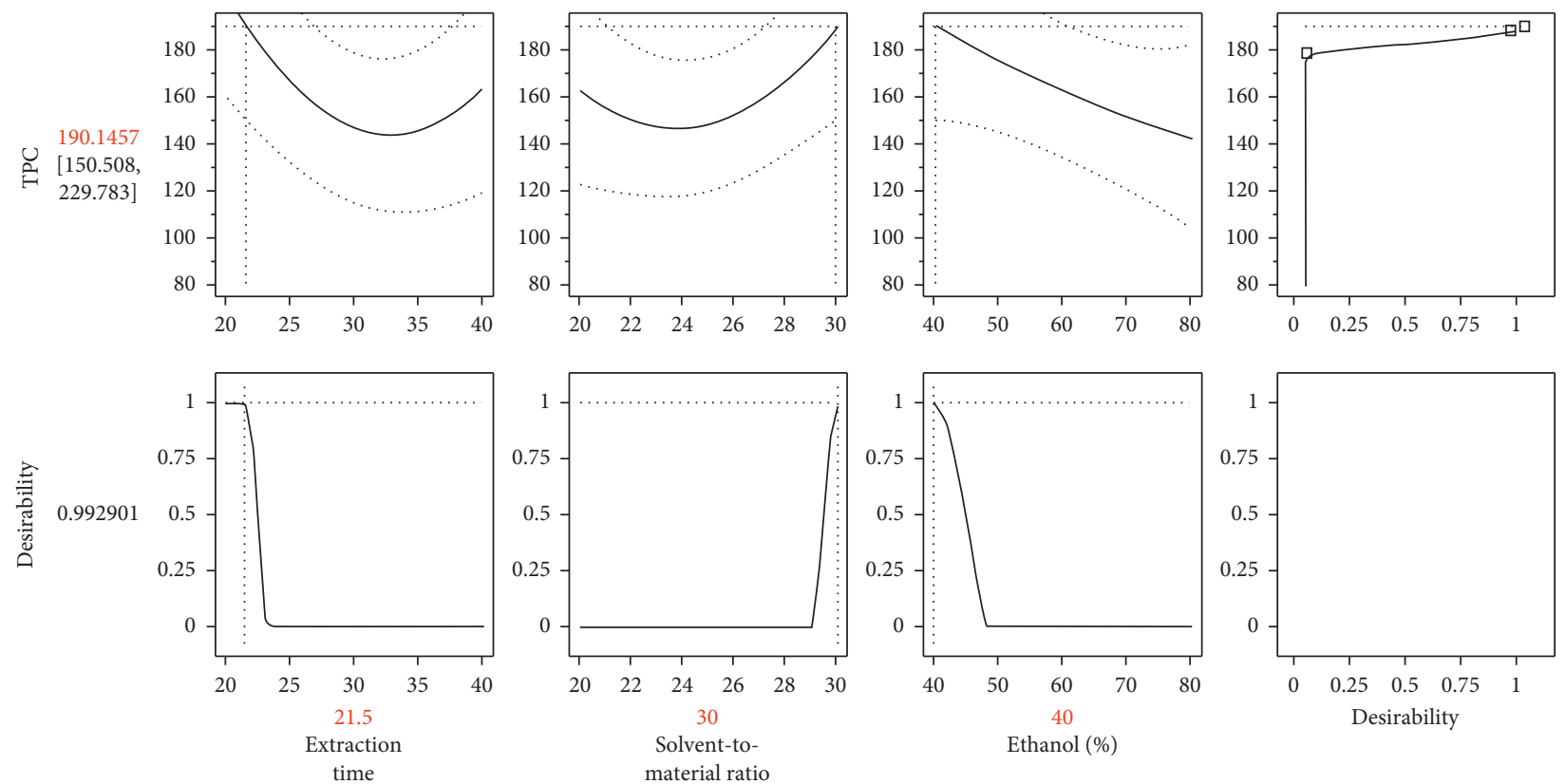

FIgURE 4: Desirability plot showing the precise operating conditions leading to the optimal TPC.

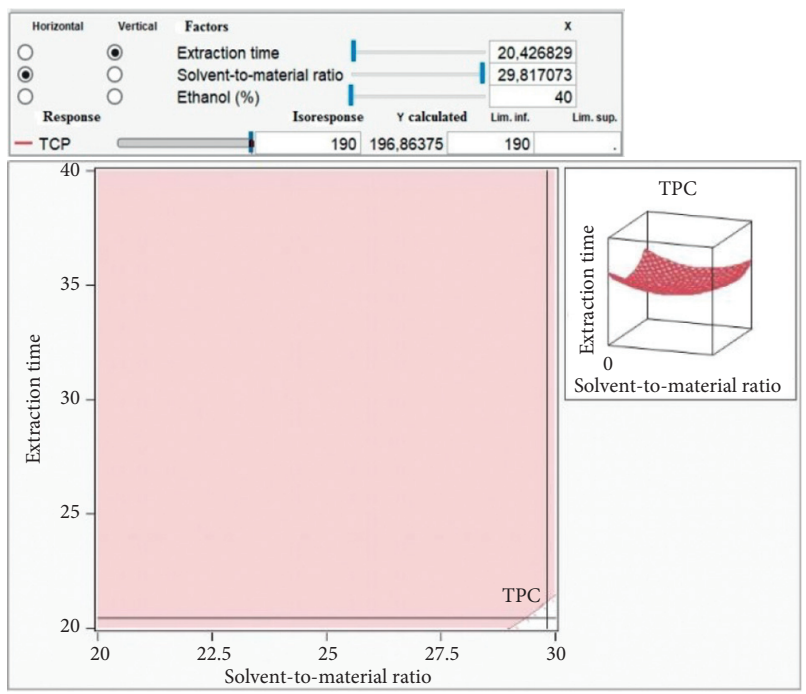

(a)



(b)

FIGURE 5: (a) Isoresponse plot showing the optimal compromise zone leading to the desired TPC (190 mg EAG/g) obtained by fixing the third parameter (ethanol (\%)) in its low level (40\%) and varying the other two parameters. (b) 3D plot of the response TPC in terms of extraction time and liquid/solid ratio effects and by fixing the concentration of ethanol at $40 \%$.

coefficient. As the extraction of phenolic compounds depends mainly on the polarity of solvents and compounds, a single solvent might not be effective for the extraction of a bioactive compound. Hence, a combination of alcohol with water is more effective in extracting phenolic compounds than alcohol alone [34]. Ethanol/water was chosen as the unique extraction solvent, instead of others, because of the low price of ethanol, low toxicity, easiness of recycling [35], and good polarity to extract the phenolic compounds. The obtained findings from our study are in agreement with previous studies, which reported that adding water to the alcohol shows a synergistic effect, increasing the extraction performance of phenolic compounds from plant samples $[36,37]$. The results of a study carried out by Guerra et al. [38] on the optimization of the parameters influencing the concentration of polyphenols obtained from mango peel by ultrasound-assisted extraction confirmed that the use of $50 \%$ ethanol made it possible to obtain optimum phenolic compounds.

The extraction time is an important parameter to minimize the energy cost of the process [39]. In our study, the total phenolic concentration increased with prolonged 

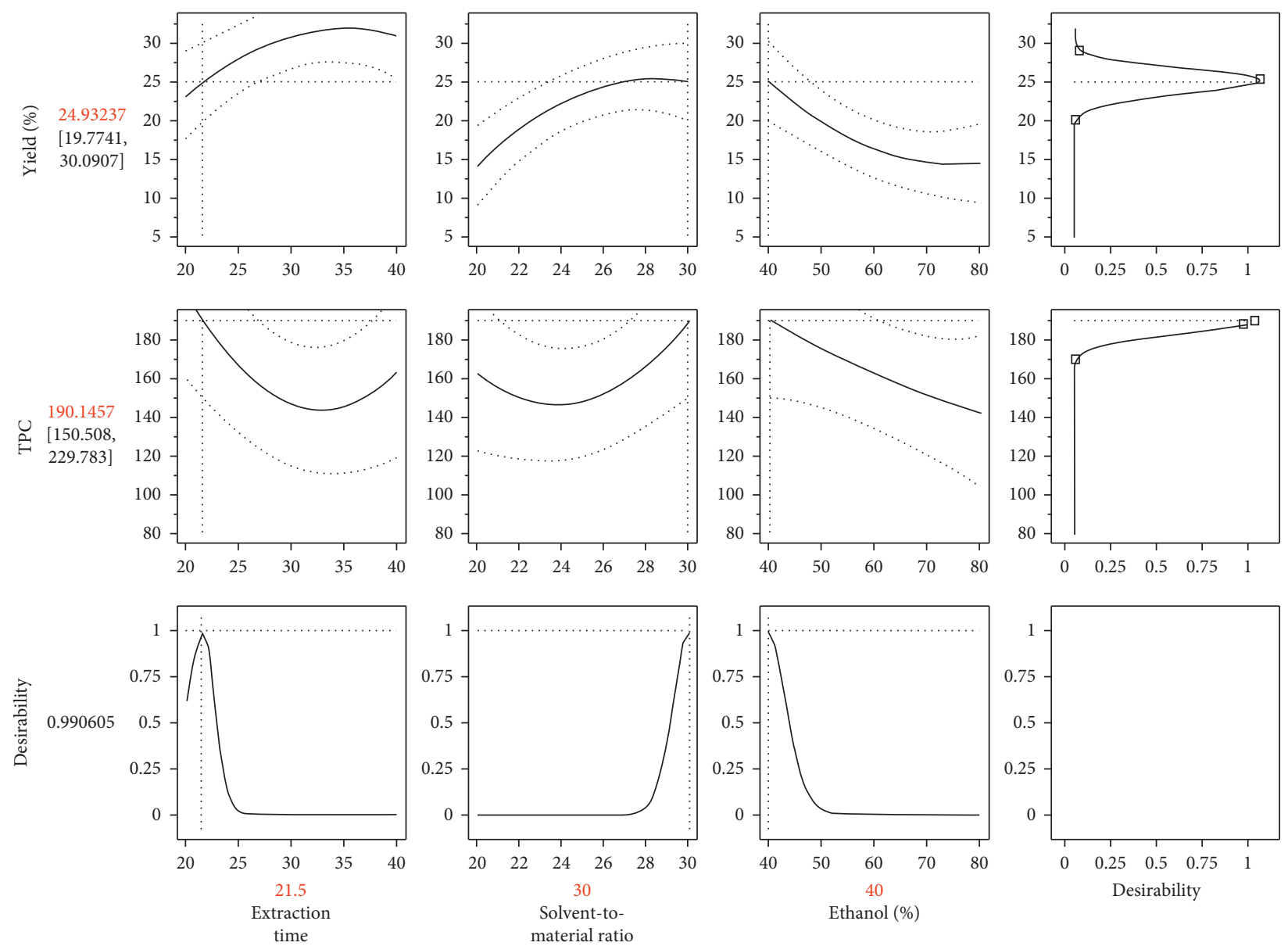

FIGURE 6: Desirability plot showing the precise operating conditions leading to the optimization of both yield and TPC responses, simultaneously.

extraction time from 20 to $40 \mathrm{~min}$. This observation was understandable because an extended extraction time favors the extraction of phenolic compounds [40]. Also, another study realized by Hammi et al [41] reported similar results while investigating the effect of time on the extraction efficiency of polyphenols from Zizyphus lotus, while other studies revealed a shorter extraction time to obtain the optimum phenolic compounds using ultrasound-assisted extraction. The optimal time for the extraction of phenolic compounds (1225.7 mg EAG/100 g of extract) from the peel of Litchi chinensis extracted by ultrasound was 30 minutes [42]. The maximum of phenolic compounds (345.81 $\pm 2.82 \mathrm{mg} \mathrm{EAG/100} \mathrm{g} \mathrm{of} \mathrm{the} \mathrm{extract)} \mathrm{from} \mathrm{the} \mathrm{stems}$ of Bactris gasipaes (Arecaceae family) was obtained during $30 \mathrm{~min}$ of extraction [43]. Recently, Iftikhar et al. [44] evaluated the total concentration of polyphenols in Secale cereale ethanolic extract (Poaceae), the extraction time to obtain the optimum TPC (245.74 mg GAE/100 g of extract) was 29 minutes. During these two studies, the extraction temperatures were 60 and $66^{\circ} \mathrm{C}$, respectively, which could explain that the researchers obtained the optimum TPC in a reduced time compared to our study (temperature of extraction at $25^{\circ} \mathrm{C}$ ).

The increased extraction of total phenolic content was observed with an increased solvent-to-material ratio from 20 to $30 \mathrm{ml} / \mathrm{g}$. This is probably due to the fact that more solvent can enter cells while more phenolic compounds can permeate into the solvent under the higher solvent-to-material ratio conditions [45]. A comparison of the literature has shown that extraction assisted by ultrasound contributes to the increase in yields of polyphenols, in addition to the preservation and growth of the biological activities of polyphenol extracts compared to traditional techniques [46]. A recent study conducted by Palsikowski et al. (2020) compared the efficiency of the extraction of leaves of Bauhinia forficata (Fabaceae family) by ultrasound and maceration methods using alcoholic solvents of different polarity 


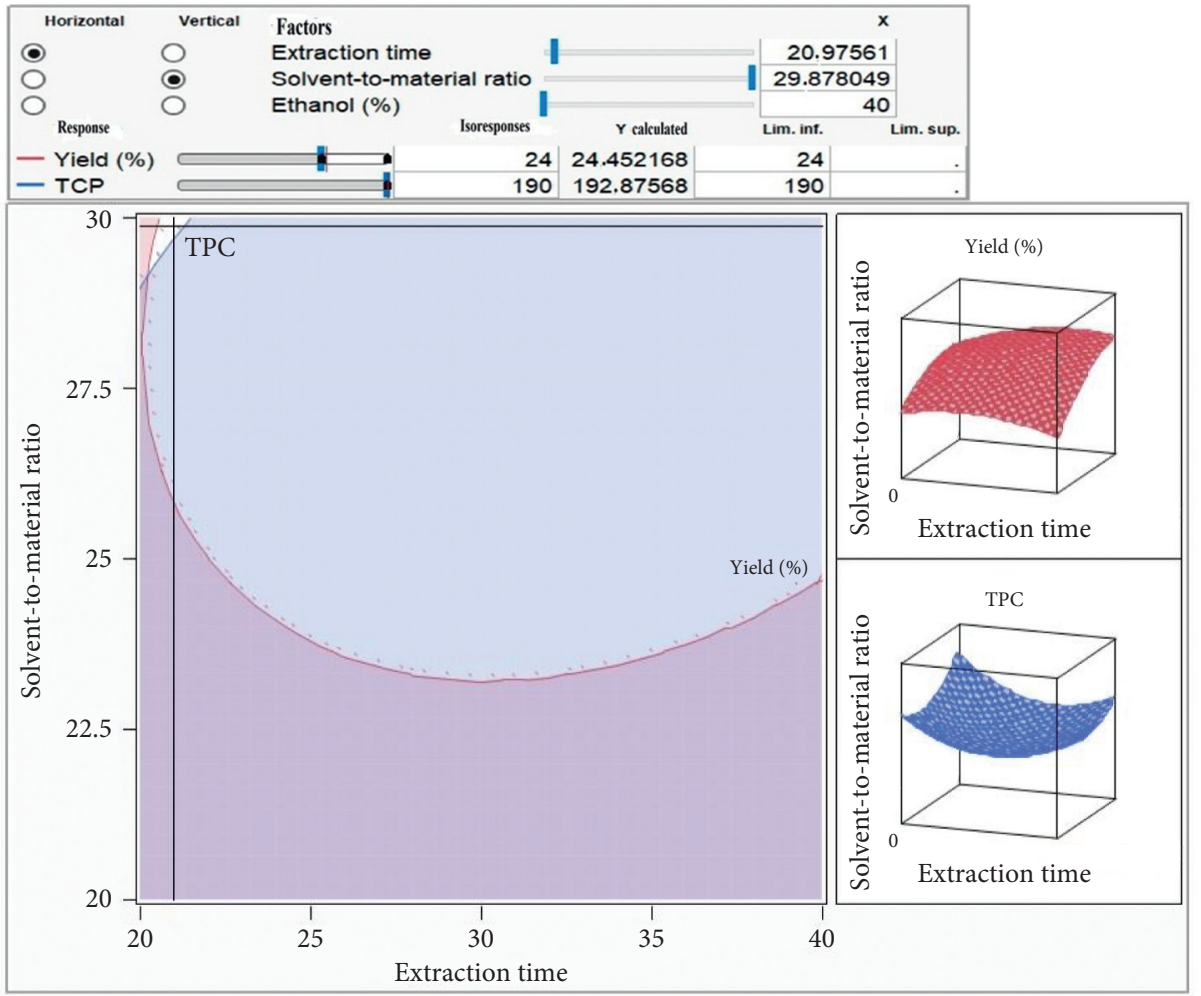

FIgURE 7: Isoresponse plot showing the precise operating conditions leading to the optimization of both yield and TPC responses, simultaneously.

TABLE 6: Theoretical and experimental responses recorded for the selected operating conditions.

\begin{tabular}{|c|c|c|c|c|c|}
\hline \multirow{2}{*}{ Extraction conditions } & & \multicolumn{2}{|c|}{ Yield (\%) } & \multicolumn{2}{|c|}{ TPC (mg GAE)/g dry matter) } \\
\hline & & Predicted yield (\%) & Experimental yield (\%) & Predicted TPC & Experimental TPC \\
\hline Time & $30 \mathrm{~min}$ & & & & \\
\hline Liquid/solid ration & $20 \mathrm{ml} / \mathrm{g}$ & 14.29 & $14.85 \pm 1.02$ & 129.75 & $130.15 \pm 2.35$ \\
\hline Concentration of ethanol & $45 \%$ & & & & \\
\hline
\end{tabular}

(hexane, ethyl acetate, and ethanol). During this study, the researchers obtained an optimum yield and total concentration of polyphenols of $8.33 \%$ and $59.47 \mathrm{mg}$ EAG/g, respectively. These results were obtained according to the following conditions: the temperature at $41^{\circ} \mathrm{C}$, the ratio solvent-material at $1 / 20(\mathrm{w} / \mathrm{v})$, and a power value of $80 \%$. The scientists proved that the ultrasonic extraction could reduce the extraction time compared to the extraction by maceration while obtaining a better concentration of phenolic compounds. Besides, ethanol was the most suitable solvent for the extraction of phenols [47].

\section{Conclusion}

The response surface methodology was successfully employed to optimize the yield and the phenolic compound extraction from Moroccan L. stoechas. The BBD proved to be a powerful tool for the optimization of ultrasonic-assisted extraction parameters. This study has permitted to define the optimal extraction process for yield response as follows: an extraction time of $34 \mathrm{~min}$, a liquid/solid ratio of $30 \mathrm{ml} / \mathrm{g}$, and an ethanol concentration of $40 \%$. The optimal conditions to obtain the highest polyphenols content, $190.14 \mathrm{mg}$ GAE/g, are as follows: extraction time of $21.5 \mathrm{~min}$, liquid/solid ratio of $30 \mathrm{ml} / \mathrm{g}$, and ethanol concentration of $40.5 \%(\mathrm{v} / \mathrm{v})$. However, for the optimization of two responses simultaneously to get a yield of $24.2 \%$ and a total concentration polyphenols of $190.24 \mathrm{mg} \mathrm{GAE} / \mathrm{g}$, the following parameters must be respected: extraction time of about $20.73 \mathrm{~min}$, liquid/solid ratio of $29.72 \mathrm{ml} / \mathrm{g}$, and ethanol concentration of $40.5 \%(\mathrm{v} / \mathrm{v})$.

The results indicated that the UAE-RSM approach was effective for maximizing the yield extraction and TPC, and the knowledge gained from this study should be useful for further exploitation and application of the phenolic compounds.

\section{Data Availability}

The data used to support the findings of this study are available from the corresponding author upon request. 


\section{Conflicts of Interest}

The authors declare that they have no conflicts of interest.

\section{References}

[1] M. Araújo, F. B. Pimentel, R. C. Alves, and M. B. P. P. Oliveira, "Phenolic compounds from olive mill wastes: health effects, analytical approach and application as food antioxidants," Trends in Food Science \& Technology, vol. 45, no. 2, pp. 200-211, 2015.

[2] M. B. Bahadori, G. Zengin, L. Dinparast, and M. Eskandani, "The health benefits of three Hedgenettle herbal teas (Stachys byzantina, Stachys inflata, and Stachys lavandulifolia)-profiling phenolic and antioxidant activities," European Journal of Integrative Medicine, vol. 36, Article ID 101134, 2020.

[3] H. Kırmızıbekmez, Y. İnan, R. Reis, H. Sipahi, A. C. Gören, and E. Yeşilada, "Phenolic compounds from the aerial parts of Clematis viticella $\mathrm{L}$. and their in vitro anti-inflammatory activities," Natural Product Research, vol. 33, pp. 2541-2544, 2019.

[4] H. B. Rashmi and P. S. Negi, "Phenolic acids from vegetables: a review on processing stability and health benefits," Food Research International, vol. 136, Article ID 109298, 2020.

[5] M. Efenberger-Szmechtyk, A. Nowak, and A. Czyzowska, "Plant extracts rich in polyphenols: antibacterial agents and natural preservatives for meat and meat products," Critical Reviews in Food Science and Nutrition, vol. 61, no. 1, pp. 149-178, 2020.

[6] D. Gómez-Maldonado, C. Lobato-Calleros, E. AguirreMandujano, S. G. Leyva-Mir, L. Robles-Yerena, and E. J. Vernon-Carter, "Antifungal activity of mango kernel polyphenols on mango fruit infected by anthracnose," $L W T$, vol. 126, Article ID 109337, 2020.

[7] V. Spínola, J. Pinto, and P. C. Castilho, "Hypoglycemic, antiglycation and antioxidant in vitro properties of two Vaccinium species from Macaronesia: a relation to their phenolic composition," Journal of Functional Foods, vol. 40, pp. 595$605,2018$.

[8] E. Gansukh, J. Gopal, D. Paul et al., "Ultrasound mediated accelerated anti-influenza activity of aloe vera," Scientific Reports, vol. 8, Article ID 17782, 2018.

[9] S. H. Haq, G. Al-Ruwaished, M. A. Al-Mutlaq et al., "Antioxidant, anticancer activity and phytochemical analysis of green algae, chaetomorpha collected from the Arabian gulf," Scientific Reports, vol. 9, Article ID 18906, 2019.

[10] Y. Ez Zoubi, D. Bousta, and A. Farah, "A phytopharmacological review of a mediterranean plant: Lavandula stoechas L." Clinical Phytoscience, vol. 6, no. 1, p. 9, 2020.

[11] J. El-Hilaly, M. Hmammouchi, and B. Lyoussi, "Ethnobotanical studies and economic evaluation of medicinal plants in Taounate province (Northern Morocco)," Journal of Ethnopharmacology, vol. 86, no. 2-3, pp. 149-158, 2003.

[12] Y. Ez Zoubi, A. Farah, H. Zaroual, and A. El Ouali Lalami, "Antimicrobial activity of Lavandula stoechas phenolic extracts against pathogenic bacteria isolated from a hospital in Morocco," Vegetos, vol. 33, no. 4, pp. 703-711, 2020.

[13] K. Canlı, A. Yetgin, A. Benek, M. E. Bozyel, and E. Murat Altuner, "In vitro antimicrobial activity screening of ethanol extract of Lavandula stoechas and investigation of its biochemical composition," Advances in Pharmacological Sciences, vol. 2019, Article ID e3201458, 6 pages, 2019.

[14] R. Baptista, A. M. Madureira, R. Jorge et al., "Antioxidant and antimycotic activities of two native Lavandula species from
Portugal," Evidence-Based Complementary and Alternative Medicine, vol. 2015, Article ID e570521, 10 pages, 2015.

[15] E. Celep, S. Akyüz, Y. İnan, and E. Yesilada, "Assessment of potential bioavailability of major phenolic compounds in Lavandula stoechas L. ssp. Stoechas," Industrial Crops and Products, vol. 118, pp. 111-117, 2018.

[16] S. B. Mustafa, M. Akram, H. Muhammad Asif et al., "Antihyperglycemic activity of hydroalcoholic extracts of selective medicinal plants Curcuma longa, Lavandula stoechas, Aegle marmelos, and Glycyrrhiza glabra and their polyherbal preparation in alloxan-induced diabetic mice," Dose-Response, vol. 17, 2019.

[17] A. H. Gilani, N. Aziz, M. A. Khan et al., "Ethnopharmacological evaluation of the anticonvulsant, sedative and antispasmodic activities of Lavandula stoechas L." Journal of Ethnopharmacology, vol. 71, no. 1-2, pp. 161-167, 2000.

[18] S. S. Kulabas, H. Ipek, A. R. Tufekci et al., "Ameliorative potential of Lavandula stoechas in metabolic syndrome via multitarget interactions," Journal of Ethnopharmacology, vol. 223, pp. 88-98, 2018.

[19] F. Algieri, A. Rodriguez-Nogales, T. Vezza et al., "Anti-inflammatory activity of hydroalcoholic extracts of Lavandula dentata L. and Lavandula stoechas L." Journal of Ethnopharmacology, vol. 190, pp. 142-158, 2016.

[20] Y. Ez zoubi, D. Bousta, L. El Mansouri et al., "Phytochemical screening, anti-inflammatory activity and acute toxicity of hydro-ethanolic, flavonoid, tannin and mucilage extracts of Lavandula stoechas L. From Morocco," International Journal of Pharmacognosy and Phytochemical Research, vol. 8, no. 1, p. 7, 2016.

[21] I. K. Karabagias, V. K. Karabagias, and K. A. Riganakos, "Physico-chemical parameters, phenolic profile, in vitro antioxidant activity and volatile compounds of ladastacho (Lavandula stoechas) from the region of Saidona," Antioxidants, vol. 8, no. 4, p. 80, 2019.

[22] T. J. Mason, "Ultrasound in synthetic organic chemistry," Chemical Society Reviews, vol. 26, no. 6, pp. 443-451, 1997.

[23] M. Saifullah, R. McCullum, A. McCluskey, and Q. Vuong, "Comparison of conventional extraction technique with ultrasound assisted extraction on recovery of phenolic compounds from lemon scented tea tree (Leptospermum petersonii) leaves," Heliyon, vol. 6, Article ID e03666, 2020.

[24] S. Chemat, A. Lagha, H. AitAmar, P. V. Bartels, and F. Chemat, "Comparison of conventional and ultrasoundassisted extraction of carvone and limonene from caraway seeds," Flavour and Fragrance Journal, vol. 19, no. 3, pp. 188-195, 2004.

[25] Y. T. Tung, W. C. Chang, P. S. Chen, T. C. Chang, and S. T. Chang, "Ultrasound-assisted extraction of phenolic antioxidants from Acacia confusa flowers and buds," Journal of Separation Science, vol. 34, no. 7, pp. 844-851, 2011.

[26] T. Martínez-Ramos, J. Benedito-Fort, N. J. Watson, I. I. RuizLópez, G. Che-Galicia, and E. Corona-Jiménez, "Effect of solvent composition and its interaction with ultrasonic energy on the ultrasound-assisted extraction of phenolic compounds from mango peels (Mangifera indica L.)," Food and Bioproducts Processing, vol. 122, pp. 41-54, 2020.

[27] C. Chen, L. Wang, R. Wang et al., "Ultrasound-assisted extraction from defatted oat (Avena sativa L.) bran to simultaneously enhance phenolic compounds and $\beta$-glucan contents: compositional and kinetic studies," Journal of Food Engineering, vol. 222, pp. 1-10, 2018.

[28] M. Irakli, P. Chatzopoulou, and L. Ekateriniadou, "Optimization of ultrasound-assisted extraction of phenolic 
compounds: oleuropein, phenolic acids, phenolic alcohols and flavonoids from olive leaves and evaluation of its antioxidant activities," Industrial Crops and Products, vol. 124, pp. 382-388, 2018.

[29] V. L. Singleton, R. Orthofer, and R. M. Lamuela-Raventós, "[14] Analysis of total phenols and other oxidation substrates and antioxidants by means of folin-ciocalteu reagent," Methods of Enzymology, vol. 299, pp. 152-178, 1999.

[30] SAS Institute Inc., JMP Version 8.0.1, SAS Institute Inc., Cary, NC, USA, 2012.

[31] A. H. Ammar, F. Zagrouba, and M. Romdhane, "Optimization of operating conditions of Tunisian myrtle (Myrtus communis L.) essential oil extraction by a hydrodistillation process using a 24 complete factorial design," Flavour and Fragrance Journal, vol. 25, no. 6, pp. 503-507, 2010.

[32] R. H. Myers, D. C. Montgomery, and C. M. Anderson-Cook, Response Surface Methodology: Process and Product Optimization Using Designed Experiments, Wiley-Blackwell, Hoboken, NJ, USA, 3rd edition, 2009.

[33] N. R. Draper and H. Smith, Applied Regression Analysis, Wiley-Interscience, Hoboken, NJ, USA, 3rd edition, 1998.

[34] M. Markom, M. Hasan, W. Daud, H. Singh, and J. Jahim, "Extraction of hydrolysable tannins from Phyllanthus niruri Linn.: effects of solvents and extraction methods," Separation and Purification Technology, vol. 52, no. 3, pp. 487-496, 2007.

[35] Y. Zhao, Y. Hou, G. Tang et al., "Optimization of ultrasonic extraction of phenolic compounds from Epimedium brevicornum maxim using response surface methodology and evaluation of its antioxidant activities in vitro," Journal of Analytical Methods in Chemistry, vol. 2014, Article ID e864654, 7 pages, 2014.

[36] Z. İlbay, S. Şahin, and Ş.İ. Kırbaşlar, "Optimisation of ultrasound-assisted extraction of rosehip (Rosa canina L.) with response surface methodology," Journal of the Science of Food and Agriculture, vol. 93, pp. 2804-2809, 2013.

[37] S. Kim, H. Murthy, E. Hahn, H. Lee, and K. Paek, "Parameters affecting the extraction of ginsenosides from the adventitious roots of ginseng (Panax ginseng C.A. Meyer)," Separation and Purification Technology, vol. 56, no. 3, pp. 401-406, 2007.

[38] A. P. Guerra, V. A. D. S. Garcia, and C. D. Silva, "Otimização da extração de compostos fenólicos da casca de manga (tommy atkins) utilizando processo assistido por ultrassom," e-Xacta, vol. 9, no. 1, pp. 103-110, 2016.

[39] L. Galvan d'Alessandro, K. Kriaa, I. Nikov, and K. Dimitrov, "Ultrasound assisted extraction of polyphenols from black chokeberry," Separation and Purification Technology, vol. 93, pp. $42-47,2012$.

[40] C. Santos-Buelga, S. Gonzalez-Manzano, M. Dueñas, and A. M. Gonzalez-Paramas, "Extraction and isolation of phenolic compounds," in Natural Products Isolation, S. D. Sarker and L. Nahar, Eds., Humana Press, Totowa, NJ, USA, pp. 427-464, 2012.

[41] K. M. Hammi, A. Jdey, C. Abdelly, H. Majdoub, and R. Ksouri, "Optimization of ultrasound-assisted extraction of antioxidant compounds from Tunisian Zizyphus lotus fruits using response surface methodology," Food Chemistry, vol. 184 , pp. 80-89, 2015.

[42] C. da Silva, V. S. Garcia, and L. S. Franciscato, "Extração assistida por ultrassom de compostos bioativos das cascas de lichia (Litchi chinensis Sonn.)," RECEN-Revista Ciências Exatas e Naturais, vol. 18, pp. 81-96, 2016.

[43] D. B. S. Donadone, C. Giombelli, D. L. G. Silva, N. Stevanato, C. da Silva, and B. C. B. Barros, "Ultrasound-assisted extraction of phenolic compounds and soluble sugars from the stem portion of peach palm," Journal of Food Processing and Preservation, vol. 44, Article ID e14636, 2020.

[44] M. Iftikhar, H. Zhang, A. Iftikhar et al., "Study on optimization of ultrasonic assisted extraction of phenolic compounds from rye bran," LWT, vol. 134, Article ID 110243, 2020.

[45] K. N. Prasad, E. Yang, C. Yi, M. Zhao, and Y. Jiang, "Effects of high pressure extraction on the extraction yield, total phenolic content and antioxidant activity of longan fruit pericarp," Innovative Food Science \& Emerging Technologies, vol. 10, no. 2, pp. 155-159, 2009.

[46] C. S. Dzah, Y. Duan, H. Zhang et al., "The effects of ultrasound assisted extraction on yield, antioxidant, anticancer and antimicrobial activity of polyphenol extracts: a review," Food Bioscience, vol. 35, Article ID 100547, 2020.

[47] P. A. Palsikowski, L. M. Besen, E. J. Klein, C. Silva, and E. A. Silva, "Optimization of ultrasound-assisted extraction of bioactive compounds from $B$. forficata subsp. Pruinosa," The Canadian Journal of Chemical Engineering, vol. 98, no. 10, pp. 2214-2226, 2020. 